\title{
Thermal degradation properties of bio-based iron alginate film
}

\author{
Yun Liu ${ }^{1 *}$, Jun-Sheng Wang ${ }^{2}$, Ping Zhu ${ }^{1 *}$, Jin-Chao Zhao ${ }^{1}$, Chuan-Jie Zhang ${ }^{1}$, Yi Guo ${ }^{1}$, Li Cui ${ }^{1}$ \\ ${ }^{1}$ College of Chemistry and Chemical Engineering, Hubei Biomass Fibers and Eco-dyeing \& Finishing Key \\ Laboratory, State Key Laboratory of New Textile Materials and Advanced Processing Technologies, Wuhan Textile \\ University, Wuhan 430073, China \\ ${ }^{2}$ Tianjin Fire Research Institute of the Ministry of Public Security, Tianjin 300381, China \\ Corresponding author: Yun Liu: Tel.: +86-027-5936 7672.E-mail address: liuyun0215@126.com. \\ Ping Zhu: Tel.: +86-027-5936 7672.E-mail address: pzhu99@163.com.
}

\begin{abstract}
The flame retardancy and pyrolysis behavior of iron alginate were investigated by a microscale combustion calorimeter (MCC), a thermogravimetric analyzer which was coupled with a Fourier transform infrared spectroscopy and a mass spectrometry (TG-FTIR-MS), and a pyrolysis-gas chromatography-mass spectrometry (Py-GC-MS), respectively. Large differences in the flame retardancy and pyrolysis behavior were observed from the MCC and Py-GC-MS results of iron alginate and sodium alginate. The MCC results showed that iron ions seriously reduced the value of peak heat release rate (PHRR) of alginate at lower temperature. TG-FTIRMS and Py-GC-MS results indicated that iron ions influenced the devolatilisation products upon pyrolysis process. The pyrolysis of iron alginate was found to yield much less gaseous products than sodium alginate. And it was suggested that the iron ions strongly catalyzed alginate to produce $\mathrm{H}_{2} \mathrm{O}, \mathrm{CO}_{2}$ and other gaseous compounds which owned lower combustion heat values, resulting in the improvement of flame retardancy for iron alginate. On the basis of the results of TG-FTIR-MS and Py-GC-MS of iron alginate, the possible thermal degradation mechanism of iron alginate was proposed. The results obtained from this study might supply useful message for comprehending the flame retardant mechanism of alginates.
\end{abstract}

Keywords: Iron Alginate; MCC; Py-GC-MS; TG-FTIR-MS; Thermal degradation mechanism 


\section{Introduction}

In the last few decades, polysaccharides, a kind of bio-based materials, have been thriving in popularity and increasing researchers are taking interest in them ${ }^{[1]}$. Cellulose and chitin, which are the most abundant polysaccharides, are not soluble in water and most of organic solvents ${ }^{[2]}$. While alginate, a kind of polysaccharide, is readily water-soluble and regarded as one of desirable candidates for wet spinning ${ }^{[2]}$. Alginate is derived from algae ${ }^{[3,4]}$. And it is a linear copolymer, and comprised of $\alpha-1,4-\mathrm{L}$-guluronate $(\mathrm{G})$ and $\beta-1,4-\mathrm{D}$-mannuronate $(\mathrm{M})$ repeating monomeric units, which arrange in an anomalous structure of changing proportions of $\mathrm{MM}, \mathrm{MG}$, GG and blocks ${ }^{[5-7]}$. The alginate has ion-exchanger roles ${ }^{[8]}$. Alginate gelation takes place when divalent or trivalent cations interact with blocks of $\mathrm{G}$ residues ${ }^{[9]}$, producing the so-called "eggbox" structure ${ }^{[10-11]}$. Alginate has increasing industrial used fields, such as in the textile printing field, paper field, food field, drug formulations and wound dressings ${ }^{[12,13]}$.

It has been known that alginate fibers and films have flame retardant properties without any addition of other flame ratardants ${ }^{[14-20]}$. Xia et al ${ }^{[15,16]}$ and zhu et al ${ }^{[17-21]}$ have investigated the effects of divalent and trivalent metal cations on the flame retardant properties, thermal degradation properties and pyrolysis properties of alginate fibers and films. The results indicated that divalent and trivalent metal ions improved the flame retardancy of alginate fibers and films, and that the addition of divalent metal ions and aluminum ions reduced the type of pyrolysis products of alginates. However, the effect of $\mathrm{Fe}^{3+}$ on the thermal degradation mechanism of alginate was also not investigated in detail. Zaafarany ${ }^{[22]}$ has studied the non-isothermal degradation of $\mathrm{Fe}, \mathrm{Cr}$ and $\mathrm{Al}$ cross-linked trivalent metal-alginate complexes using thermogravimetry (TG) techniques in static air. The results revealed the formation of metal hydroxide, oxalate and carbonate for $\mathrm{Al}^{3+}, \mathrm{Cr}^{3+}$ and $\mathrm{Fe}^{3+}$-alginate complexes. And they were followed by degradation of these intermediate fragments to the corresponding metal oxides as the final products; however, Zaafarany did not investigate the effects of trivalent cations on the pyrolysis process of alginate.

In our previous work ${ }^{[20]}$, the flame retardant properties, thermal degradation properties of trivalent metal-alginate films, including aluminum alginate and iron alginate, have been reported; however, the pyrolysis mechanism of iron alginate is not included. And in another our previous work ${ }^{[18]}$, the pyrolysis behavior and mechanism of aluminum alginate have been reported. The results indicated that the addition of aluminum ions changed the thermal degradation process, producing fewer pyrolysis products. Does the addition of iron ions take the same effect on the pyrolysis properties? Understanding the effect of iron ions on the thermal degradation of alginate during pyrolysis is useful for well understanding the flame retardant mechanism of alginate. The purpose of this research is to extend the previous work to explore the effects of iron ions on the pyrolysis process and the pyrolysis mechanism of alginate, further to investigate the flame retardant mechanism of trivalent metal alginates.

In the present work, the flame retardant properties and pyrolysis behaviors of iron alginate were studied by microscale combustion calorimeter (MCC), thermogravimetric analyzer which was coupled with Fourier transform infrared spectroscopy and mass spectrometry (TG-FTIRMS), and pyrolysis-gas chromatography-mass spectrometry (Py-GC-MS). And the effect of iron ions on the pyrolysis process and pyrolysis mechanism of iron alginate was proposed on the basis of the results of TG-FTIR-MS and Py-GC-MS.

\section{Experimental}




\subsection{Materials}

Sodium alginate powder $\left(\mathrm{M}_{\mathrm{n}}=357,475, \mathrm{M}_{\mathrm{n}} / \mathrm{M}_{\mathrm{w}}=1.392, \mathrm{M} / \mathrm{G}=0.32\right)$ was purchased from Qingdao Mingyue Co. Ltd (China), and used as-received. Iron chloride was supplied by Sinopharm Chemical Reagent Co., Ltd (China), and was an analytical reagent.

\subsection{Preparation of iron alginate}

Sodium alginate aqueous solutions $(5 \mathrm{wt} \%)$ were prepared in a beaker with a vigorous stirrer for $4 \mathrm{~h}$. Then the obtained solution was cast into a sheet with suitable thickness and size, and dried under room temperature for $3 \mathrm{~d}$. When they were dried, the films were removed and immersed in iron chloride aqueous solutions $(5 \mathrm{~mol} / \mathrm{L})$ for $2 \mathrm{~h}$. After coagulation, the films were washed in order to take the unreacted iron chloride away. And then the film was put into a vacuum drying for $24 \mathrm{~h}$.

The limiting oxygen index (LOI) value of iron alginate film was $35.3 \%$, and the UL-94 rating was $\mathrm{V}-0$ rating ${ }^{[20]}$.

\subsection{Measurements}

\subsubsection{Microscale Combustion Calorimeter}

Microscale combustion calorimeter (MCC) measurement was carried out by a micro-scale combustion calorimeter (Govmak MCC-2) on the basis of ASTM D7309-2007. $5 \pm 0.1 \mathrm{mg}$ of samples was heated to $750{ }^{\circ} \mathrm{C}$ in nitrogen with a flowing rate of $80 \mathrm{~mL} / \mathrm{min}$, and the heating rate was set to be $1{ }^{\circ} \mathrm{C} / \mathrm{s}$. The anaerobic and volatile pyrolysis products in the nitrogen gas stream were blended with a $20 \mathrm{~mL} / \mathrm{min}$ stream of oxygen before entering a $900{ }^{\circ} \mathrm{C}$ combustor. Each sample was carried out in three replicates, and the reproducibility was $\pm 5 \%$.

\subsubsection{Thermogravimetric Analyzer-Fourier Transform Infrared Spectroscopy-Mass Spectrometry}

A thermogravimetric analyzer (NETZSCH TG 449C, Germany) coupled with a Fourier transform infrared spectroscopy (Bruker Tensosr 27 FTIR, Germany) and a mass spectrometry (NETZSCH QMS 403C, Germany) (TG-FTIR-MS) was utilized to study the thermal stability of iron alginate and the formation of volatiles produced in the thermal degradation process. About $10 \mathrm{mg}$ iron alginate was put into the furnace and heated with a heating rate of $10{ }^{\circ} \mathrm{C} / \mathrm{min}$ from room temperature to $800{ }^{\circ} \mathrm{C}$ with a nitrogen flowing rate of $100 \mathrm{~mL} / \mathrm{min}$. The FTIR instrument was linked to the TG instrument through a stainless pipe and a flow cell. And the pipe and cell were preheated to $180{ }^{\circ} \mathrm{C}$ to prevent the evolved gases from condensing. Through the FTIR realtime tracking on the gases produced in the thermal degradation process, the spectra for volatile evolution during iron alginate thermal degradation process were recorded by the FTIR real-time tracking mode. The scanning range was from 4000 to $400 \mathrm{~cm}^{-1}$. A mass spectrometer was connected to the thermobalance to detect the gaseous compounds produced during thermal degradation process. The gas ionization was carried out at $100 \mathrm{eV}$.

TG of iron alginate was carried out in duplicate. The mass was reproducible to within \pm $0.1 \%$, and the temperature of the instrument was reproducible to within $\pm 1{ }^{\circ} \mathrm{C}$.

\subsubsection{Pyrolysis-Gas Chromatography-Mass Spectrometry}

The fast pyrolysis analyzer (CDS5200) was connected with gas chromatography-mass spectrometry systems (Py-GC-MS) (Perkin Elmer Clarus680GC-SQ8MS) to study the formation of volatiles from iron alginate fast pyrolysis process against chemical reaction temperature. The 
carrier gas was He, and about $300 \mu \mathrm{g}$ of iron alginate was placed into the pyrolysis tube. The pyrolysis temperature of the furnace was $700{ }^{\circ} \mathrm{C}$, and the flash heating rate was $20{ }^{\circ} \mathrm{C} / \mathrm{ms}$. The remaining time for the sample was set to be $15 \mathrm{~s}$, to make most of the solid sample pyrolyzed. The gaseous compounds produced in the pyrolysis process were identified by GC-MS. The conditions for GC-MS test were as follows: the chromatographic separation was carried out using a $0.25 \mathrm{~mm}$ HP-5 capillary column; the temperature of the chromatographic column was set to be from $40{ }^{\circ} \mathrm{C}(3 \mathrm{~min})$ to $280{ }^{\circ} \mathrm{C}(5 \mathrm{~min})$ with a heating rate of $10{ }^{\circ} \mathrm{C} / \mathrm{min}$; the injector temperature was maintained at $280{ }^{\circ} \mathrm{C}$; the mass spectra were performed in electron ionization (EI) mode at $70 \mathrm{eV}$. The yields of the gaseous compounds were determined by means of the characterized GC-MS spectrums, on the basis of the database from NIST library.

\section{Results and discussion}

\subsection{Microscale Combustion Calorimetry}

Microscale combustion calorimetry (MCC), a kind of pyrolysis-combustion flow calorimetry, has dynamic capability to investigate heat release rate (HRR); what is more, MCC uses a few milligram sizes to avoid the samples preparation problems faced for cone calorimetry ${ }^{[23,24]}$. The HRR curves of iron alginate and sodium alginate as a function of temperature is shown in Figure 1, and the data obtained from MCC test are listed in Table 1. From Figure 1, it is noted that iron alginate and sodium alginate show HRR curves with two peaks. The first peak heat release rate (PHRR) of iron alginate and sodium alginate take place with PHRR values of 15.5 and $105 \mathrm{~W} / \mathrm{g}$ at 135 and $230{ }^{\circ} \mathrm{C}$, respectively; The second one appears with PHRR values of 29.6 and 31.4 $\mathrm{W} / \mathrm{g}$ at 219 and $453{ }^{\circ} \mathrm{C}$. Compared to HRR curve of sodium alginate, it is observed that the results show two distinct characteristics because of the addition of iron ions. Firstly, there is a significant decrease in HRR values of iron alginate. Secondly, the first PHRR value takes place at lower temperature. This suggests that the addition of iron ions can promote the thermal degradation of alginate and catalyze alginate to form more amounts of inflammable gases, such as $\mathrm{CO}_{2}$ and $\mathrm{H}_{2} \mathrm{O}$. And this results in reducing the release of flammable gases at lower temperature. However, the HRR values of iron alginate are similar with those values of sodium alginate at higher temperature, suggesting that iron ions do not have the flame retardant effect on alginate at higher temperature. From Figure 1 and Table 1, it can be obtained that the residual amount of iron alginate, $28.2 \%$, is much lower than that of sodium alginate, $47.4 \%$; while the HRR values of iron alginate are much lower than those of sodium alginate. This indicates that the addition of iron ions can catalyze alginate to produce more inflammable gases, such as $\mathrm{CO}_{2}$ and $\mathrm{H}_{2} \mathrm{O}$, showing better flame retardant properties of iron alginate. 


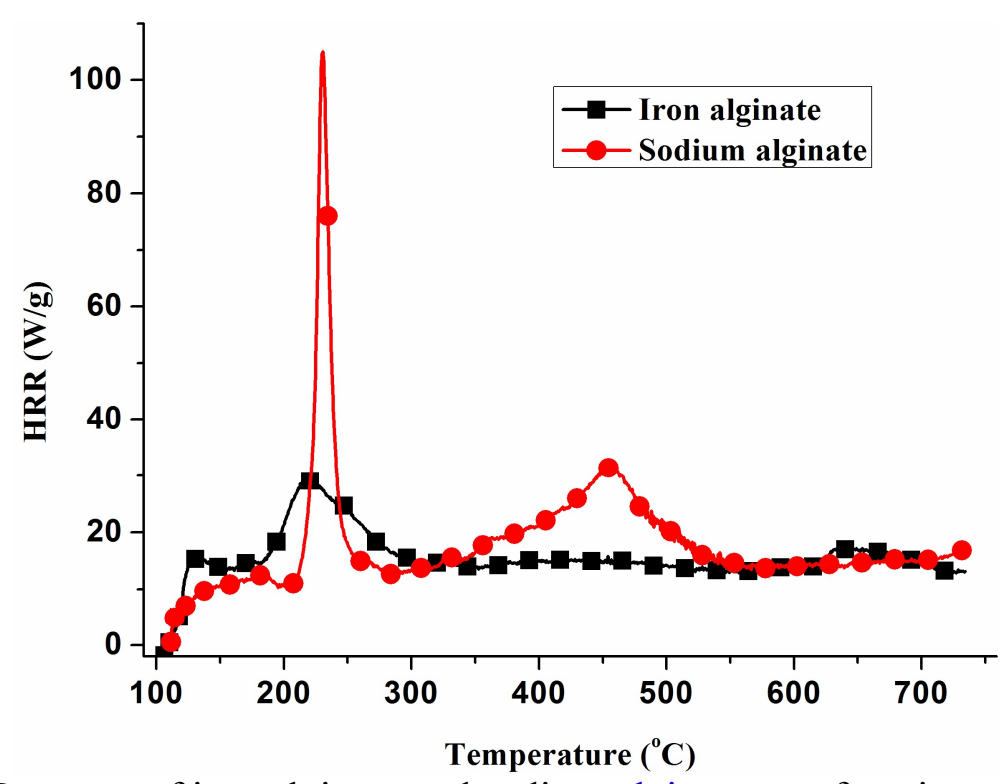

Figure $1 \mathrm{HRR}$ curves of iron alginate and sodium alginate as a function of temperature

Table 1 Data obtained from the MCC parameters of iron alginate and sodium alginate

\begin{tabular}{cccccc}
\hline Sample & $\begin{array}{c}\mathrm{PHRR}_{1} \\
(\mathrm{~W} / \mathrm{g})\end{array}$ & $\begin{array}{c}\mathrm{T}_{\mathrm{PHRR} 1} \\
\left({ }^{\circ} \mathrm{C}\right)\end{array}$ & $\begin{array}{c}\mathrm{PHRR}_{2} \\
(\mathrm{~W} / \mathrm{g})\end{array}$ & $\begin{array}{l}\mathrm{T}_{\mathrm{PHRR} 2} \\
\left({ }^{\circ} \mathrm{C}\right)\end{array}$ & $\begin{array}{c}\text { Residues } \\
(\%)\end{array}$ \\
\hline Iron alginate & 15.5 & 135 & 29.6 & 219 & 28.2 \\
Sodium alginate & 105.0 & 230 & 31.4 & 453 & 47.4 \\
\hline
\end{tabular}

\subsection{TG-FTIR-MS analysis}

TG analysis coupled with mass spectrometry (MS) and fourier transform infrared spectrometry (FTIR) allows to comform the proposed general thermal degradation mechanism of bio-based materials ${ }^{[25]}$.

\subsubsection{Temperature-programmed thermal degradation}

The thermogravimetric analysis (TG) and their differential thermogravimetric analysis (DTG) curves of iron alginate at a heating rate of $10{ }^{\circ} \mathrm{C} / \mathrm{min}$ in $\mathrm{N}_{2}$ with a flowing rate of $100 \mathrm{~mL} / \mathrm{min}$ are shown in Figure 2. The main loss stage of iron alginate take place in a wide temperature zoon (from 170 to $400{ }^{\circ} \mathrm{C}$ ), and then iron alginate begins to degrade slowly with quite lower thermal degradation rates. The onset thermal degradation temperature ( $5 \mathrm{wt} \%$ mass loss) of iron alginate is $181{ }^{\circ} \mathrm{C}\left(\mathrm{T}_{\text {onset }}\right)$. And then, the faster thermal degradation of iron alginate takes place with further increasing of temperature. The peak of mass loss rate, $5.6 \% / \mathrm{min}$, appears around $198{ }^{\circ} \mathrm{C}$ $\left(\mathrm{T}_{\max }\right)$. From room temperature to $600{ }^{\circ} \mathrm{C}$, about $68.6 \%$ of the total weight is rapidly decomposed. The weight loss is ascribed to the intensive evolution of small gaseous molecules and the thermal degradation of alginate with the fracture of glycosidic bonds, releasing incombustible such as $\mathrm{CO}_{2}$ and $\mathrm{H}_{2} \mathrm{O}$. Then, the formed intermediate compounds further decompose to produce the more 
stable intermediate compounds at a slower rate of decomposition with increasing the temperature. The amount of char residue at $800{ }^{\circ} \mathrm{C}$ is about $28.3 \%$.

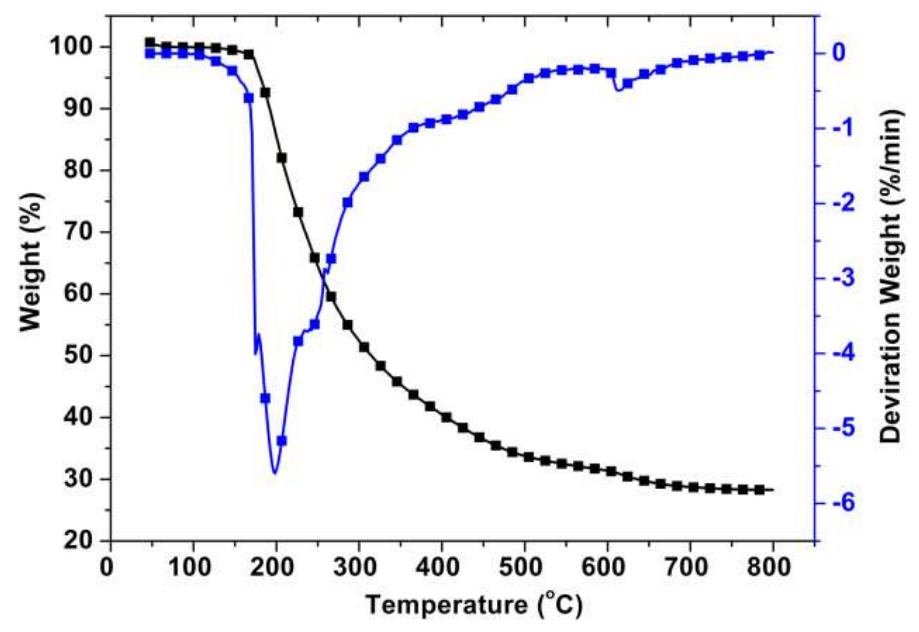

Figure 2 TG and DTG curves of iron alginate

\subsubsection{Evolved gas analysis during thermal degradation process of iron alginate}

Generally speaking, chemical reactions taking place during alginate thermal degradation involved dehydroxylation, decarboxylation, decarbonylation, rearrangement, scission and condensation reactions. The reactions produce gases and char residues; some of the released gaseous compounds can be investigated by FTIR and MS techniques.

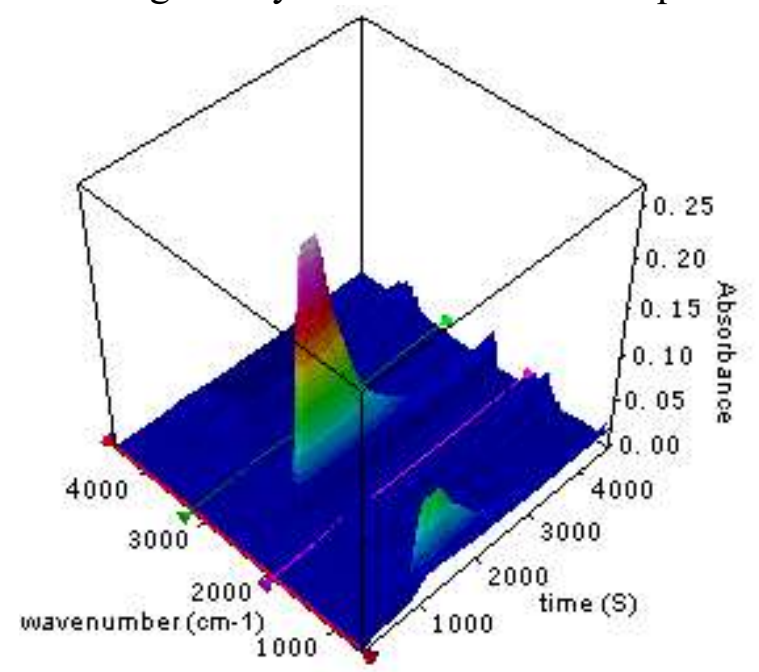

Figure $33 \mathrm{D}$ infrared spectra of evolved gases during iron alginate pyrolysis

FTIR is often utilized to differentiate a variety of organic and inorganic gas compounds for thermal degradation of polymeric materials ${ }^{[26]}$. 3D FTIR spectra of the evolution gases from iron alginate thermal degradation process including information of infrared absorbance, wavenumber and time are presented in Figure 3. According to the infrared spectra, the change in spectral intensity with time direction is as the same as TG results. Absorbance information at different 
wavenumber and time can be observed from 3D FTIR spectra of iron alginate. It can be obtained from Figure 3 that most of the gases are evolved between 1000 and $3000 \mathrm{~s}$ and the evolved gases are mainly composed of $\mathrm{H}_{2} \mathrm{O}\left(3750-3500 \mathrm{~cm}^{-1}\right)$ and $\mathrm{CO}_{2}\left(2363\right.$ and $\left.667 \mathrm{~cm}^{-1}\right)$. When further increasing the temperature, the absorbances of carbon monoxide, $\mathrm{C}=\mathrm{O}$ and $\mathrm{C}=\mathrm{C}$ appear at 21862109 and 1800-1600 $\mathrm{cm}^{-1}$, respectively, resulting from the further thermal degradation of fragments formed. Some typical FTIR spectra of the thermal degradation gaseous compounds were chosen for primary analysis at different temperature. According to the TG data in Figure 2, the spectra obtained at $150,181,198,210,250,300,400,450$ and $500{ }^{\circ} \mathrm{C}$ are shown in Figure $4 \mathrm{a}$ and $4 \mathrm{~b}$.

From Figure $4 \mathrm{a}$ and $4 \mathrm{~b}$, it can be observed that the evolved gases of iron alginate thermal degradation are distinguished by the characteristic absorbance. In the beginning thermal degradation stage at $150{ }^{\circ} \mathrm{C}, \mathrm{H}_{2} \mathrm{O}$ and $\mathrm{CO}_{2}$, the absorbance intensities of which are very weak, are shown in wavenumbers 3968-3496, 1515 and 2383-2317 $\mathrm{cm}^{-1}$, which may be resulted from the releases of $\mathrm{CO}_{2}$ and $\mathrm{H}_{2} \mathrm{O}$ adsorbed by furnace. With temperature increased to $181{ }^{\circ} \mathrm{C}, \mathrm{T}_{\text {onset, }}$, stronger $\mathrm{CO}_{2}$ stretching absorbance waves take place at about 2357 and $667 \mathrm{~cm}^{-1}$, which indicates the start of thermal degradation of iron alginate. The similar infrared absorbance of iron alginate thermal degradation is obained at 181 and $198{ }^{\circ} \mathrm{C}\left(\mathrm{T}_{\max }\right)$, while the absorbance intensities at $198{ }^{\circ} \mathrm{C}$ are stronger than those at $181{ }^{\circ} \mathrm{C}$. With the temperature increases, intensities of the absorbance waves are enhanced to some extent, and then reduced, which are accordant with TG results. On the basis of the Lambert-Beer law, the absorption spectra at a specific wavenumber linearly rely on the gas concentration ${ }^{[27]}$. Thus, the change of absorbance intensity in the entire thermal degradation process reflects the concentration change of the gaseous compounds. It can be seen from Figure $4 \mathrm{a}$ and $4 \mathrm{~b}$ that the new absorbance waves at 2179 and $2113 \mathrm{~cm}^{-1}$, which are attached to the stretching of carbon monoxide, appear when the temperature increases above $250{ }^{\circ} \mathrm{C}$. The $\mathrm{C}=\mathrm{O}$ and $\mathrm{C}=\mathrm{C}$ stretching absorbance peaks in 1879$1600 \mathrm{~cm}^{-1}$ represent the release of gaseous compounds containing aldehyde or ketone or organic acid or alkene groups. And the bands in 3968-3496 and $1515 \mathrm{~cm}^{-1}$ are attributed to O-H stretching of water and -OH of organic acid or alcohols. The peak at $2937 \mathrm{~cm}^{-1}$ is attributed to the stretching of saturated hydrocarbon bonds. The intensity of absorption wave in $3014 \mathrm{~cm}^{-1}$, which attached to the stretching of unsaturated hydrocarbon bonds, increases with the increase of the temperature. And this indicates that unsaturated hydrocarbon compounds form at higher temperature because of the thermal degradation of fragments.

In order to analyze exhaustively the tendencies of absorption intensity for some functional groups with the increase of temperature, kinds of FTIR spectra for different functional groups are chosen for primary analysis at a function of temperature. According to Figure $4 \mathrm{a}$ and $4 \mathrm{~b}$, the main gaseous products emitted from thermal degradation process of iron alginate are $\mathrm{H}_{2} \mathrm{O}, \mathrm{CO}_{2}$, $\mathrm{CO},=\mathrm{C}-\mathrm{H}$ groups, $\mathrm{C}-\mathrm{H}$ groups and $\mathrm{C}=\mathrm{O}$ groups. The unambiguous wavenumbers of the spectrum peak for the volatile mentioned above are presented as follows : $\mathrm{H}_{2} \mathrm{O}, 3733 \mathrm{~cm}^{-1} ; \mathrm{CO}_{2}$, $2357 \mathrm{~cm}^{-1}$; CO, $2179 \mathrm{~cm}^{-1}$; =C-H, $3014 \mathrm{~cm}^{-1}$; C-H, $2937 \mathrm{~cm}^{-1} ; \mathrm{C}=\mathrm{O}, 1740 \mathrm{~cm}^{-1}$. And the FTIR spectra of different groups mentioned above are depicted in Figure 5. It is noted from Figure 5 that the absorbance intensities of $\mathrm{H}_{2} \mathrm{O}, \mathrm{C}=\mathrm{O}$ groups, $\mathrm{C}-\mathrm{H}$ groups first increase quickly, decrease, and then increase slowly with increasing the temperature. The absorbance intensities of $\mathrm{CO}$ experience two lowering elevated process with the temperature increasing. The absorbance intensities of $\mathrm{CO}_{2}$ and $=\mathrm{CH}$ - groups first increase and then decrease. It can be observed that $\mathrm{H}_{2} \mathrm{O}$, $\mathrm{CO}_{2}$, gaseous products containing - $\mathrm{CO}$ - groups and compounds containing - $\mathrm{CH}$ - groups are firstly produced at the initial thermal degradation process of iron alginate (at about $170{ }^{\circ} \mathrm{C}$ ). 
However, $\mathrm{CO}$ and compounds containing $=\mathrm{CH}$ - groups are generated from 223 to $750{ }^{\circ} \mathrm{C}$ and from 357 to $750{ }^{\circ} \mathrm{C}$, respectively. As can be seen from Figures 2 and 5 that $\mathrm{H}_{2} \mathrm{O}, \mathrm{CO}_{2}$, gaseous products containing - $\mathrm{CO}$ - groups and compounds containing - $\mathrm{CH}$ - groups are mainly yielded in the major loss stage of iron alginate (from 170 to $400{ }^{\circ} \mathrm{C}$ ). While $\mathrm{CO}$ and products containing $=\mathrm{CH}$ - groups are mainly produced at higher temperature zone. This indicates that the fragments formed at lower temperature further degrade to release $\mathrm{CO}$ and compounds containing $=\mathrm{CH}$ functional groups at higher temperature zone. And according to the results of MCC and FTIR, the higher HRR values are not generated from the combustion of $\mathrm{CO}$ and compounds containing $=\mathrm{CH}$ - functional groups.

According to the results mentioned above, the chemical reactions of dehydroxylation, decarboxylation and the fracture of glycosidic bonds appear at the initial thermal degradation process of iron alginate to form the fragments. And this results in the release of $\mathrm{H}_{2} \mathrm{O}, \mathrm{CO}_{2}$, gaseous products containing - $\mathrm{CO}$ - groups and products containing - $\mathrm{CH}$ - groups. With temperature increases, the fragments formed further degrade to produce more stable residues, releasing $\mathrm{H}_{2} \mathrm{O}, \mathrm{CO}_{2}$, $\mathrm{CO}$, products containing - $\mathrm{CO}$ - groups, products containing - $\mathrm{CH}$ - groups and products containing $=\mathrm{CO}$ - groups. And the thermal degradation mechanism of iron alginate will be discussed in detail in 3.4 . 

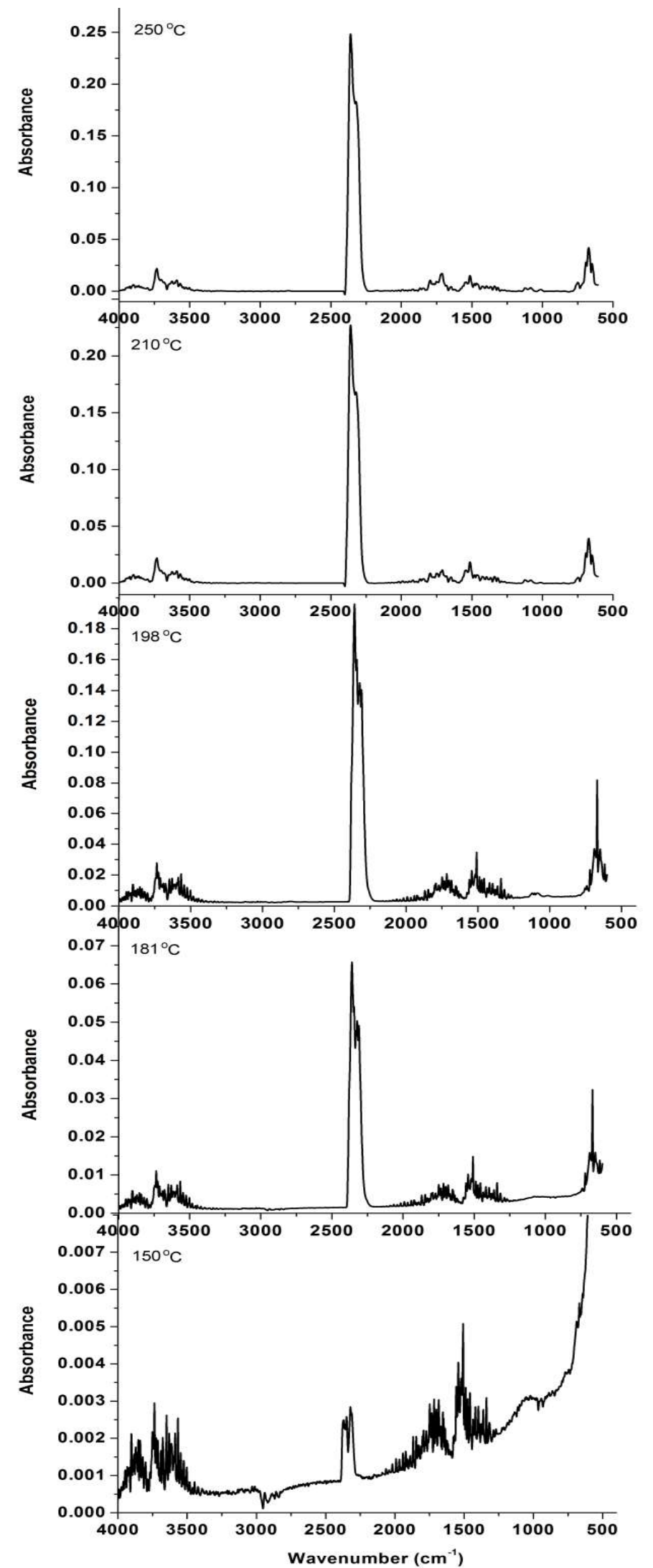

Figure 4a FTIR spectra for the evolved gaseous products in gas phase of iron alginate 


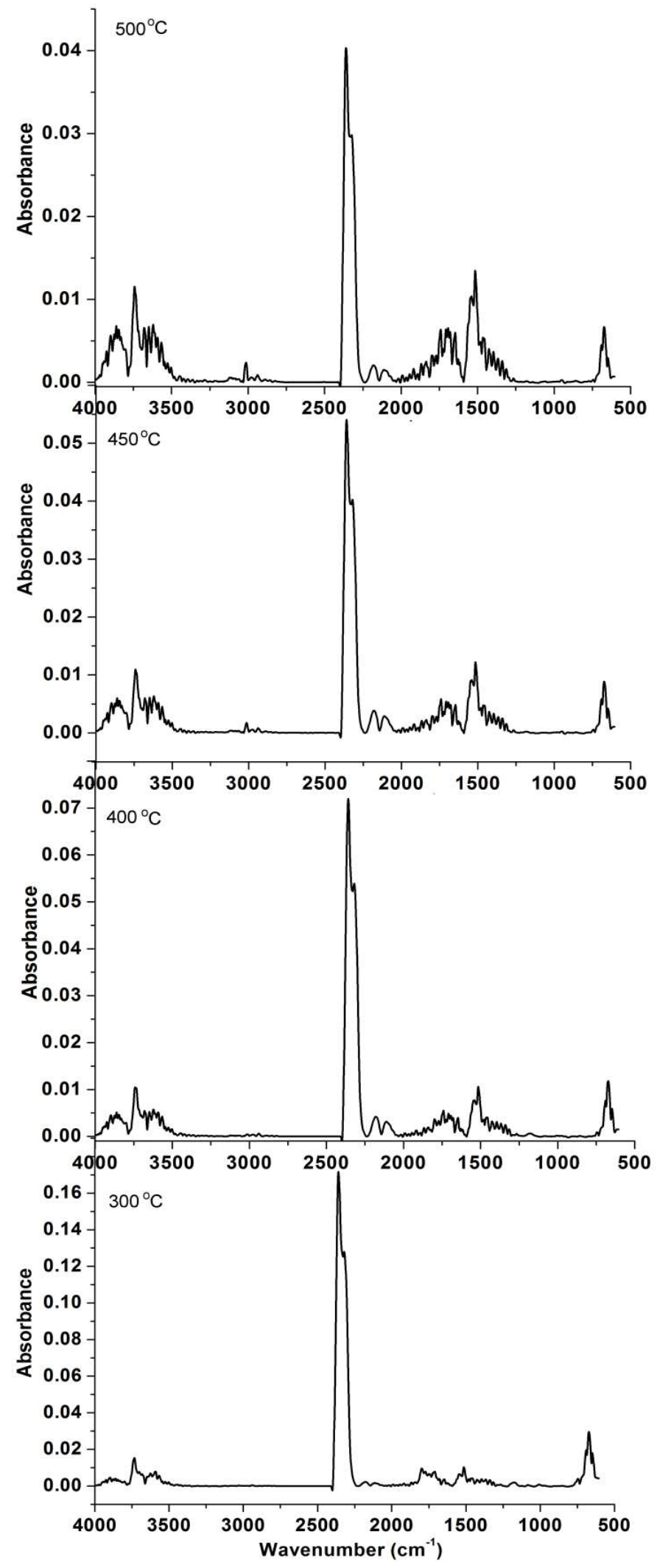

Figure $4 \mathrm{~b}$ FTIR spectra for the evolved gaseous products in gas phase of iron alginate 

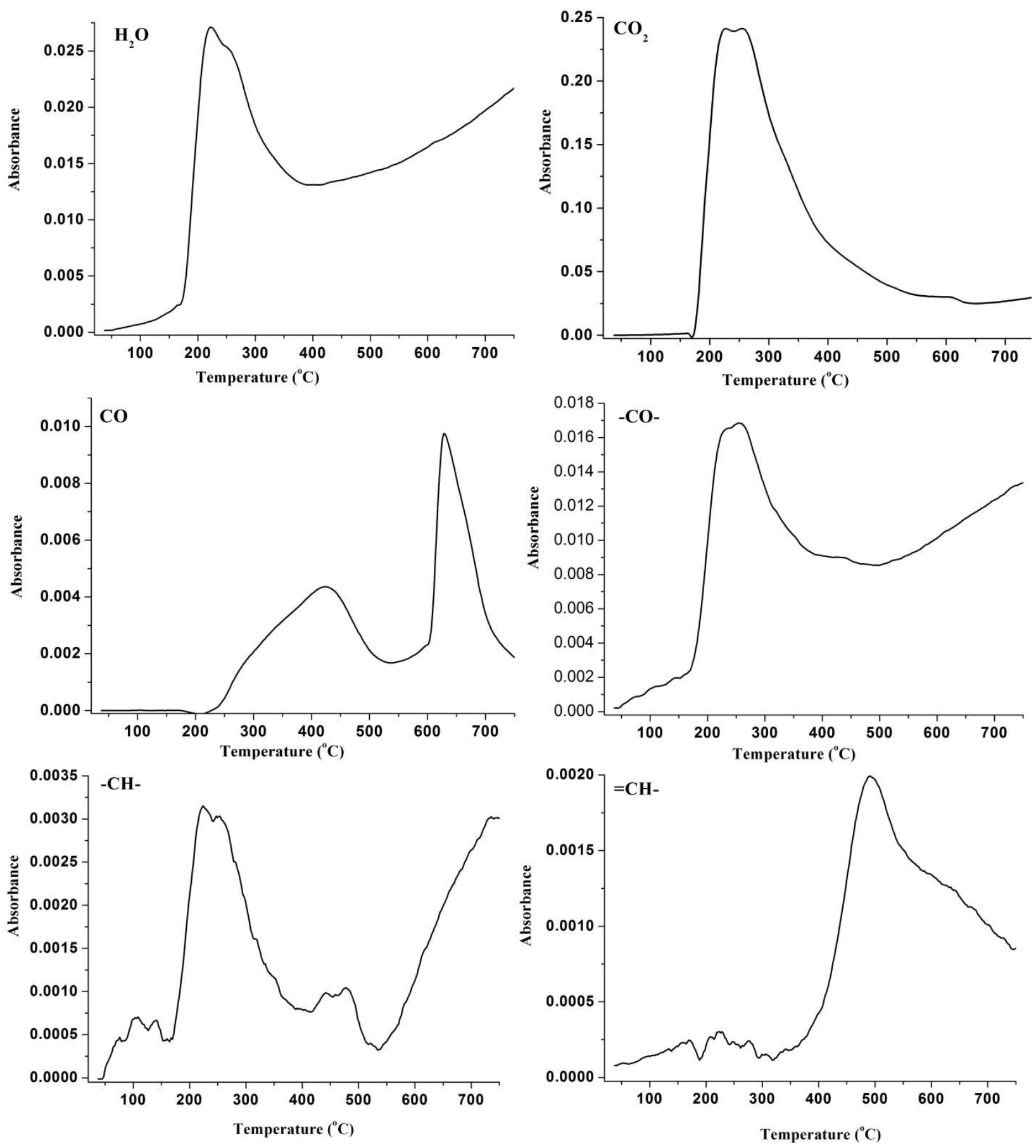

Figure 5 FTIR spectra of typical groups as a function of temperature for iron alginate

Figure 6 presents the evolution of main gas products with temperature increases during iron alginate thermal degradation according to the ion intensities from MS. The main mass spectra (MS) in the TG process of iron alginate thermal degradation by TG coupled with MS analysis are as follows: in the plot of the ion intensity corresponds with the first TG step, fragments at $\mathrm{m} / \mathrm{z} 17$ 
$\left(\mathrm{HO}^{+}\right), 18\left(\mathrm{H}_{2} \mathrm{O}\right)$ and $44\left(\mathrm{CO}_{2}\right)$ prove the release of $\mathrm{H}_{2} \mathrm{O}{ }^{[28]}$ and $\mathrm{CO}_{2}{ }^{[29]}$. This indicates the chemical reactions of dehydroxylation and decarboxylation take place in the degradation process of iron alginate. $\mathrm{H}_{2} \mathrm{O}$ and $\mathrm{CO}_{2}$ evolutions are mainly concentrated from 158 to $400{ }^{\circ} \mathrm{C}$, and the releases of them are in agreement with weight loss thermogravimetric data. It can be observed from Figure 6 that different trends of $\mathrm{H}_{2} \mathrm{O}$ and $\mathrm{CO}_{2}$ are observed that the intensities of $\mathrm{CO}_{2}$ increase first and then decrease with increasing the temperature and reach the strongest peak at $200{ }^{\circ} \mathrm{C}$; however, intensities of $\mathrm{H}_{2} \mathrm{O}$ decrease first at lower temperature, and then increase, then decrease again at higher temperature, with increasing the temperature and reach the strongest peak at $204{ }^{\circ} \mathrm{C}$. The reason is that iron alginate contains crystallization $\mathrm{H}_{2} \mathrm{O}$ which can be released in the lower temperature. $\mathrm{H}_{2} \mathrm{O}$ might produce from the evolution of bound water, crystallization water and the break of $-\mathrm{OH}$ groups in iron alginate. $\mathrm{CO}_{2}$ mainly formed from break of $-\mathrm{COO}^{-}$groups in the chain of alginate and the degradation process of iron alginate. The thermal degradation mechanism of iron alginate will be discussed in 3.4.

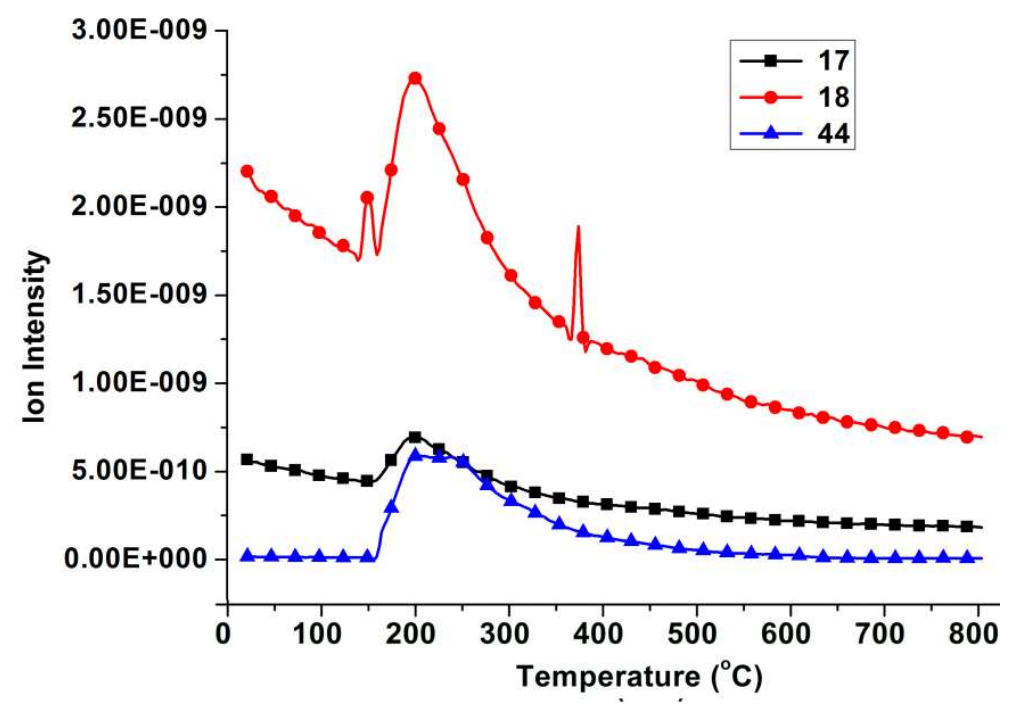

Figure 6 Evolution curves of $M / Z=17,18$ and 44 during pyrolysis of iron alginate

\subsection{Fast pyrolysis of iron alginate versus Py-GC-MS}

The other way to investigate pyrolysis evolved components of bio-based materials is to utilize Py-GC-MS, which involves the characteristics of gaseous pyrolysis compounds ${ }^{[28]}$. In order to study the composition of gaseous compounds in iron alginate pyrolysis process, pyrolysis gas chromatography and mass spectrometry (Py-GC-MS) analysis on iron alginate had been explored. On the basis of the NIST library, the highest possibility of products identification was acquired. The total ion intensity of gases evolving from iron alginate pyrolysis is shown in Figure 7. Peaks of the major products were marked with numbers. Over 20 peaks are depicted on the chromatograms, and about 20 major compounds are identified, whose structures are characterized in Table 2 (the peak numbers in Figure 7 are in accordance with the labels in Table 2). From Figure 7 and Table 2, it is noted that the major compounds are as follows: $\mathrm{CO}_{2}$, furfural, 3-penten-1-ol, 2-cetobutyric acid methyl ester, 2, 3-butanedione, and the yield of them is $78.2 \%$. Among the compounds, $\mathrm{CO}_{2}$ and furfural are the typical products of iron alginate pyrolysis, the yield of which is $64.5 \%$. And the possible thermal degradation mechanism of iron alginate will be investigated in 3.4 . 


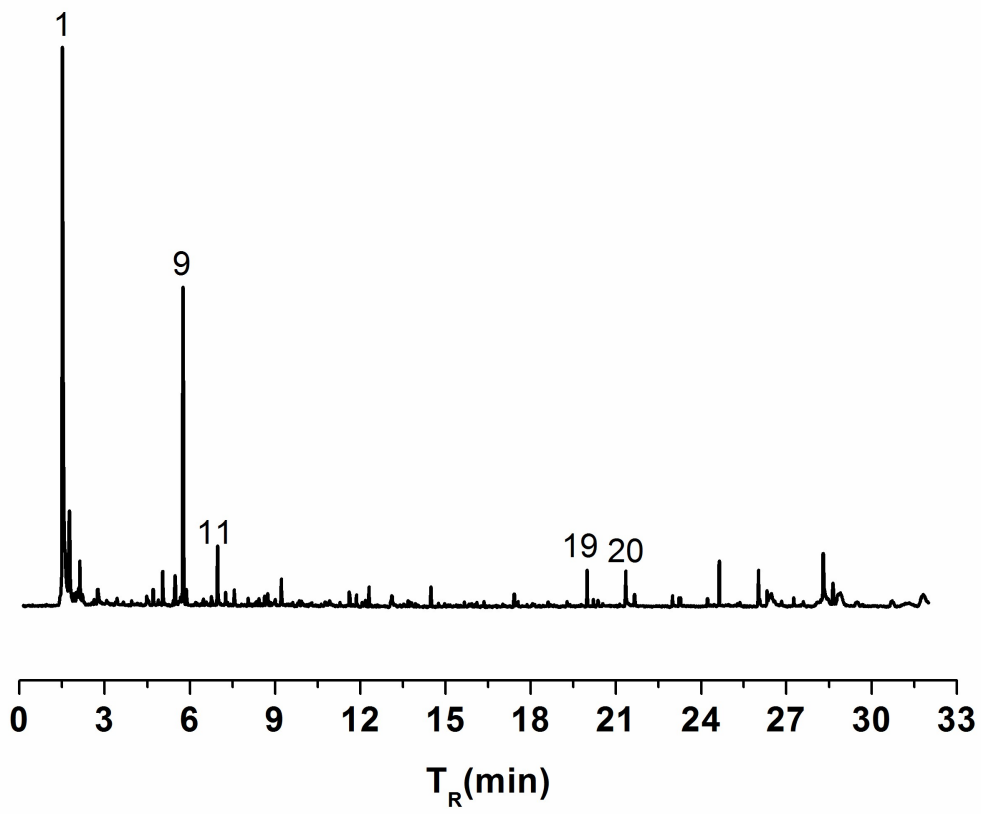

Figure 7 Py-GC-MS detection of gaseous compounds obtained from pyrolysis of iron alginate

Table 2 Results of chemical formation pyrolysis products for iron alginate at $700{ }^{\circ} \mathrm{C}$

\begin{tabular}{|c|c|c|c|c|c|c|}
\hline label & $t_{R}(\min )$ & $\begin{array}{l}\text { Molecular } \\
\text { formula }\end{array}$ & Name of compound & Molecular structure & $\begin{array}{l}\mathrm{M}_{\mathrm{w}} \\
(\mathrm{g} / \mathrm{mol})\end{array}$ & $\begin{array}{l}\text { Peak } \\
\text { area (\%) }\end{array}$ \\
\hline 1 & 1.51 & $\mathrm{CO}_{2}$ & carbon dioxide & $\mathrm{O}=\mathrm{C}=\mathrm{O}$ & 44 & 41.1 \\
\hline 2 & 1.76 & $\mathrm{C}_{5} \mathrm{H}_{10} \mathrm{O}$ & 3-penten-1-ol & & 86 & 6.2 \\
\hline 3 & 2.12 & $\mathrm{C}_{4} \mathrm{H}_{6} \mathrm{O}_{2}$ & 2,3-butanedione & & 86 & 3.1 \\
\hline 4 & 2.74 & $\mathrm{C}_{6} \mathrm{H}_{6}$ & benzene & & 78 & 1.1 \\
\hline 5 & 3.44 & $\mathrm{C}_{5} \mathrm{H}_{8} \mathrm{O}_{2}$ & 2-methyl methacrylate & & 100 & 0.5 \\
\hline 6 & 4.48 & $\mathrm{C}_{7} \mathrm{H}_{8}$ & Toluene & & 92 & 0.7 \\
\hline 7 & 4.70 & $\mathrm{C}_{4} \mathrm{H}_{6} \mathrm{O}_{2}$ & 1,4-butanedial & & 86 & 1.2 \\
\hline 8 & $\begin{array}{l}5.05 \\
7.26\end{array}$ & $\mathrm{C}_{4} \mathrm{H}_{4} \mathrm{O}_{2}$ & $2(5 \mathrm{H})$-furanone & & 84 & 2.5 \\
\hline 9 & 5.78 & $\mathrm{C}_{5} \mathrm{H}_{4} \mathrm{O}_{2}$ & furfural & & 96 & 23.4 \\
\hline
\end{tabular}




\begin{tabular}{|c|c|c|c|c|c|c|}
\hline 10 & 6.76 & $\mathrm{C}_{5} \mathrm{H}_{4} \mathrm{O}_{2}$ & $\begin{array}{l}\text { 5-methylenefuran- } \\
\text { 2(5H)-one }\end{array}$ & $=0$ & 96 & 0.7 \\
\hline 11 & 6.97 & $\mathrm{C}_{5} \mathrm{H}_{8} \mathrm{O}_{3}$ & $\begin{array}{l}\text { 2-cetobutyric acid, } \\
\text { methyl ester }\end{array}$ & & 116 & 4.4 \\
\hline 12 & 7.55 & $\mathrm{C}_{5} \mathrm{H}_{6} \mathrm{O}_{2}$ & 1,2-cyclopentanedione & & 98 & 1.2 \\
\hline 13 & 9.22 & $\mathrm{C}_{5} \mathrm{H}_{4} \mathrm{O}_{3}$ & 2H-pyran-3,4-dione & & 112 & 2.0 \\
\hline 14 & 11.61 & $\mathrm{C}_{6} \mathrm{H}_{12} \mathrm{O}_{3}$ & $\begin{array}{l}\text { 1,2-O-isopropylidene } \\
\text { Glycerol }\end{array}$ & & 132 & 1.1 \\
\hline 15 & 11.86 & $\mathrm{C}_{9} \mathrm{H}_{18} \mathrm{O}_{4}$ & $\begin{array}{l}\text { tetrahydropyranyldiet } \\
\text { hyleneglycol }\end{array}$ & & 190 & 0.9 \\
\hline 16 & 12.31 & $\mathrm{C}_{6} \mathrm{H}_{10} \mathrm{O}_{2}$ & 2-oxacycloheptanone & & 114 & 1.5 \\
\hline 17 & 13.11 & $\mathrm{C}_{8} \mathrm{H}_{12} \mathrm{O}_{2}$ & $\begin{array}{l}\text { 5,5- } \\
\text { dimethylcyclohexane- } \\
\text { 1,3-dione }\end{array}$ & & 140 & 0.8 \\
\hline 18 & 14.49 & $\mathrm{C}_{6} \mathrm{H}_{14} \mathrm{O}_{3}$ & trimethylolpropane & & 134 & 1.5 \\
\hline 19 & 19.98 & $\mathrm{C}_{17} \mathrm{H}_{34} \mathrm{O}_{2}$ & $\begin{array}{l}\text { propan-2-yl } \\
\text { tetradecanoate }\end{array}$ & & 270 & 2.7 \\
\hline 20 & 21.35 & $\mathrm{C}_{16} \mathrm{H}_{32} \mathrm{O}_{2}$ & hexadecanoic acid & & 256 & 2.6 \\
\hline
\end{tabular}

Compared to the pyrolysis products of sodium alginate ${ }^{[30]}$, there are less pyrolysis products in iron alginate pyrolysis process, which suggest iron ions could have the catalyzed effect on some chemical reaction happened during the pyrolysis process of alginate, resulting in the less gaseous compounds releasing. And this indicates that Iron ions had changed the pyrolysis process of alginate, favoring the dehydration, decarbonylation and decarboxylation of alginate except the depolymerization of alginate to further product combustible gaseous compounds. Under conditions of fast pyrolysis of alginate, disproportionation, dehydration, decarbonylation and decarboxylation reactions of various volatile products are all possible ${ }^{[31]}$. Due to the catalysis effect of iron compounds, these chemical reactions mentioned above could be more efficient and selective ${ }^{[32]}$. And most of the fragments formed might be changed to water, $\mathrm{CO}_{2}$ and furfural on the catalysis effect of compounds containing iron. And the possible pyrolysis mechanism of iron alginate will be investigated in 3.4. 


\subsection{The possible pyrolysis mechanism of iron alginate}

On the basis of the product distribution from iron alginate pyrolysis, carbon dioxide, furfural, 3penten-1-ol, 2, 3-butanedione and 2-cetobutyric acid methyl ester are the major compounds, the yields of which are $78.2 \%$ in total. While the yield of $\mathrm{CO}_{2}, 41.1 \%$, is much higher than that of furfural, 23.4\%. On the basis of the analysis of TG-FTIR-MS and Py-GC-MS, the proposed pyrolysis mechanism of iron alginate is proposed to partial fragmentation of iron alginate by means of two major processes (a lower temperature thermal degradation process and a higher temperature thermal degradation process). The speculative pyrolysis mechanism of iron alginate is presented in Figure 8. TG-FTIR-MS indicated that the evolutions of $\mathrm{CO}_{2}, \mathrm{H}_{2} \mathrm{O}$, compounds containing - $\mathrm{CO}$ - groups and compounds containing- $\mathrm{CH}$ - groups began at $170{ }^{\circ} \mathrm{C}$ and reached the maximum at $256{ }^{\circ} \mathrm{C}$ for $\mathrm{CO}_{2}$ and at $223{ }^{\circ} \mathrm{C}$ for other chemicals mentioned above. According to this results of TG-FTIR-MS, it could be speculated that decarboxylation, esterification and fracture of glycosidic bonds with the evolution of $\mathrm{H}_{2} \mathrm{O}$ and $\mathrm{CO}_{2}$, which could be catalyzed by iron ions, are estimated to be favorable at lower temperature. However, the chemical reactions of decarboxylation and fracture of glycosidic bonds are more advanced than that of esterification and fracture of glycosidic bonds on the basis of the different yields of $\mathrm{CO}_{2}$ and furfural. The pyrolysis of alginate with the fracture of glycosidic bonds to produce intermediate compounds takes place; and the reason is that the thermal stability of $\mathrm{C}-\mathrm{O}$ bonds is less than that of $\mathrm{C}-\mathrm{C}$ bonds in the hexatomic ring structure of alginate ${ }^{[33]}$. And on the catalysis effect of compounds containing iron produced, some of the intermediate compounds underwent kinds of dehydration, rearrangement, decarboxylation, scission, condensation, and decarbonylation reactions to form a kinds of lower molecular weight compounds, such as $\mathrm{H}_{2} \mathrm{O}, \mathrm{CO}_{2}$, furfural, $\mathrm{CO}$ and 2, 3butanedione. With the temperature increases, the other gaseous products and residues can form residual chars, $\mathrm{CO}, \mathrm{H}_{2} \mathrm{O}, 2(5 \mathrm{H})$-furanone and 2-cetobutyric acid methyl ester and so on at higher temperature. There are also kinds of linear gaseous compounds, like 3-penten-1-ol, propan-2-yl tetradecanoate and hexadecanoic acid, which were produced through the hexatomic ring scission, following by dehydration and decarbonylation reactions at higher temperature ${ }^{[34]}$.

As discussed above, the compounds containing iron had the catalysis effect on the iron alginate pyrolysis process, producing more amount of $\mathrm{CO}_{2}, \mathrm{H}_{2} \mathrm{O}$ and other compounds with lower heat of combustion values. The residual char formed in the pyrolysis process of iron alginate protected the matrix from the mass and heat transfer. Both of these improve the flame retardant properties of iron alginate. As mentioned above, the flame retardant mechanism of iron alginate is the combination of gas-phased flame retardant mechanism and condense-phased flame retardant mechanism. 


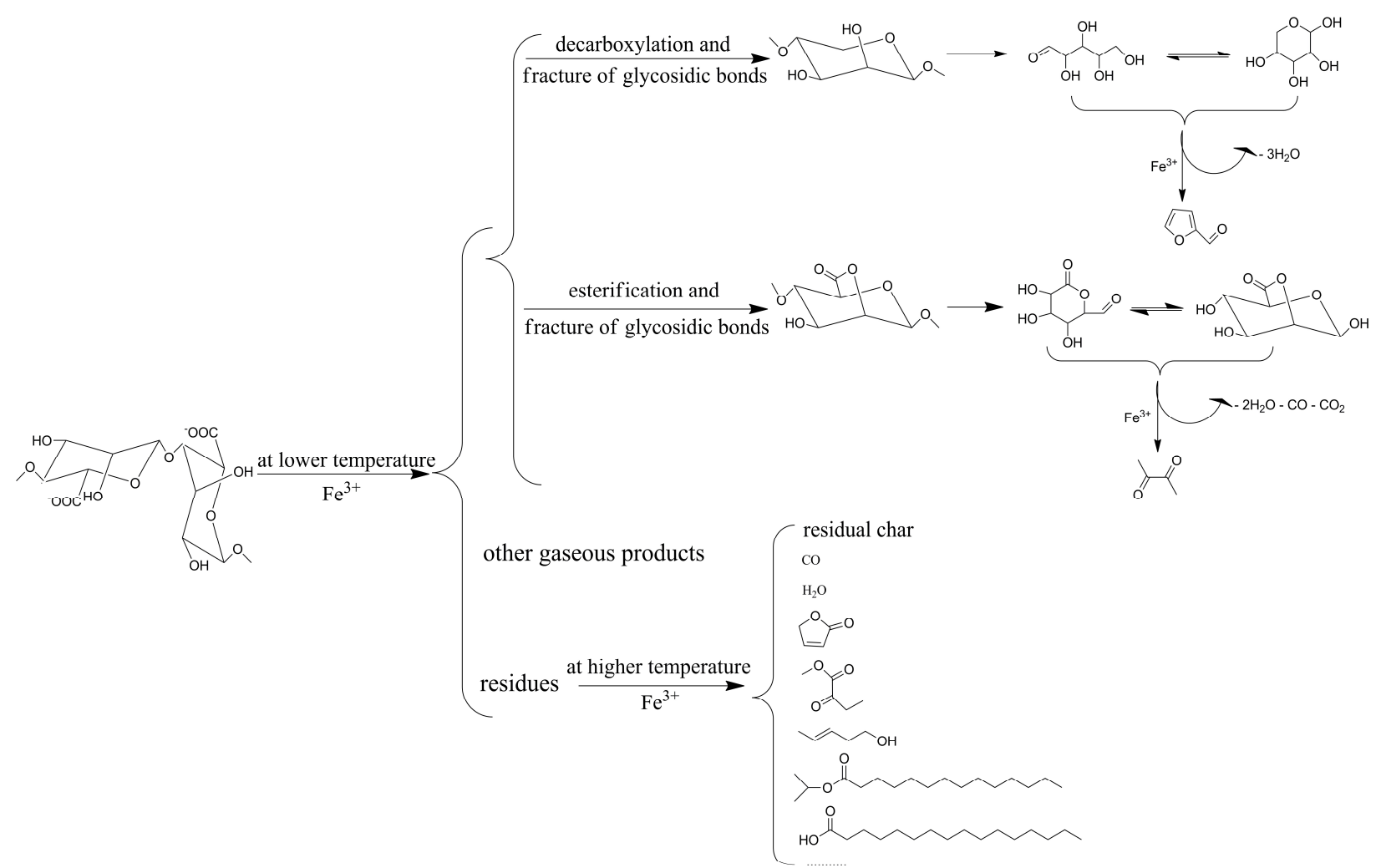

Figure 8 Speculative pyrolysis mechanism of iron alginate

\section{Conclusions}

Large differences in the flame retardancy and pyrolysis behavior were observed from the iron alginate and sodium alginate investigated by MCC and Py-GC-MS. The PHRR value of iron alginate was much lower than that of sodium alginate. The pyrolysis of iron alginate was found to yield much less products than sodium alginate. The iron ions appeared to exhibit a significant effect on the pyrolysis behavior of alginate. TG-FTIR-MS and Py-GC-MS results showed that iron ions might catalyze some chemical reaction on the pyrolysis process of alginate and change the pyrolysis process of alginate, releasing $\mathrm{H}_{2} \mathrm{O}, \mathrm{CO}_{2}$ and other gaseous compounds with lower heat of combustion values. The results obtained from this study supplied some beneficial massage for comprehending the flame retardant mechanism of alginate and designing biomaterials with better flame retardant properties.

\section{Acknowledgments}

The authors acknowledge the financial support of the Project of the National Science Foundation of China (51203126) and China Scholarship Council (CSC: 201308420380).

\section{References}

[1] J.M. Paquez, M. Deléglise, M.F. Lacrampe, P. Krawczak, Thermosetting (bio)materials derived from renewable resources: a critical review, Prog. Polym. Sci. 35 (2010) 487-509.

[2] W. Shen, Y.L. Hsieh, Biocompatible sodium alginate fibers by aqueous processing and physical crosslinking, Carbohyd. Polym. 102 (2014) 893-900. 
[3] T.S. Pathak, J.H. Yun, S.J. Lee, D.J. Baek, K.J. Paeng, Effect of cross-linker and cross-linker concentration on porosity, surface morphology and thermal behavior of metal alginates prepared from algae (Undaria pinnatifida), Carbohyd. Polym. 78 (2009) 717-724.

[4] H.B. Chen, Y.Z. Wang, M. Sánchez-Soto, D.A. Schiraldi, Low flammability, foam-like materials based on ammonium alginate and sodium montmorillonite clay, Polymer. 53 (2012) $5825-5831$.

[5] J. Comaposada, P. Gou, B. Marcos, J. Arnau, Physical properties of sodium alginate solutions and edible wet calcium alginate coatings, LWT- Food Sci. Technol. 64 (2015) 212-219.

[6] M. Bruchet, A. Melman, Fabrication of patterned calcium cross-linked alginate hydrogel films and coatings through reductive cation exchange, Carbohyd. Polym. 131 (2015) 57-64.

[7] N. Shaari, S.K. Kamarudin, Chitosan and alginate types of bio-membrane in fuel cell application: An overview, J. Power Sources. 289 (2015) 71-80.

[8] A.B. Ross, K. Anastasakis, M. Kubachi, J.M. Jones, Investigation of the pyrolysis behaviour of brown algae before and after pre-treatment using PY-GC/MS and TGA, J. Anal. Appl. Pyrol. 85 (2009) 3-10.

[9] T.R. Cuadros, O. Skurtys, J.M. Aguilera, Mechanical properties of calcium alginate fibers produced with a microfluidic device, Carbohyd. Polym. 89 (2012) 1198-1206.

[10] S.K. Papageorgiou, E.P. Kouvelos, E.P. Favvas, A.A. Sapalidis, G.E. Romanos, F.K. Katsaros, Metal-carboxylate interactions in metal-alginate complexes studied with FTIR spectroscopy, Carbohyd. Res. 345 (2010) 469-473.

[11] E.D.T. Atkins, I.A. Nieduszynski, W. Mackie, K.D. Parker, E.E. Smolko, Structural components of alginic acid. II. The crystalline structure of poly- $\alpha$-L-guluronic acid. Results of X-ray diffraction and polarized infrared studies, Biopolymers. 12 (1973) 1879-1887.

[12] A.B. Ross, C. Hall, K. Anastasakis, A. Westwood, J.M. Jones, R.J. Crewe. Influence of cation on the pyrolysis and oxidation of alginates, J. Anal. Appl. Pyrol. 91 (2011) 344-351.

[13] Y.M. Qin. Alginate fibres: an overview of the production processes and applications in wound management, Polym. Int. 57 (2008) 171-180.

[14] J.J. Zhang, Q. Ji, X.H. Shen, Y.Z. Xia, L.W. Tan, Q.S. Kong. Pyrolysis products and thermal degradation mechanism of intrinsically flame-retardant calcium alginate fibre, Polym. Degrad. Stab. 96 (2011) 936-942.

[15] J.J. Zhang, Q. Ji, F.J. Wang, L.W. Tan, Y.Z. Xia. Effects of divalent metal ions on the flame retardancy and pyrolysis products of alginate fibres, Polym. Degrad. Stab. 97 (2012) 10341040.

[16] Q.S. Kong, B.B. Wang, Q. Ji, Y.Z. Xia, Z.X. Guo, J. Yu. Thermal degradation and flame retardancy of calcium alginate fibers, Chin. J. Polym. Sci. 27 (2009) 807-812.

[17] Y. Liu, J.C. Zhao, C.J. Zhang, Y. Guo, L. Cui, P. Zhu, D.Y. Wang. Bio-based nickel alginate and copper alginate films with excellent flame retardancy: preparation, flammability and thermal degradation behavior. RSC Adv. 5 (2015) 64125-64137.

[18] Y. Liu, Z.F. Li, J.S. Wang, P. Zhu, J.C. Zhao, C.J. Zhang, Y. Guo, X. Jin, Thermal degradation and pyrolysis behavior of aluminum alginate investigated by TG-FTIR-MS and Py-GC-MS, Polym. Degrad. Stab. 118 (2015) 59-68.

[19] Y. Liu, J.C. Zhao, C.J. Zhang, H. Ji, P. Zhu, The Flame Retardancy, Thermal Properties, and Degradation Mechanism of Zinc Alginate Films, J. Macromol. Sci. B 53 (2014) 10741089. 
[20] Y. Liu, J.S. Wang, J.C. Zhao, C.J. Zhang, J.H. Ran, P. Zhu, The flame retardancy and thermal degradation behaviors of trivalent metal-alginate films, Nanomater. Energy. 3 (2014) 3-10.

[21] Y. Liu, J.C. Zhao, C.J. Zhang, Y. Guo, P. Zhu, D.Y. Wang, Effect of manganese and cobalt ions on flame retardancy and thermal degradation of bio-based alginate film, J. Mater. Sci. 51 (2016) 1052-1065.

[22] I.A. Zaafarany, Non-isothermal decomposition of Al, Cr and Fe cross-linked trivalent metalalginate complexes. J. Nucl. Relat. Technol. 7 (2010) 84-93.

[23] C.Q. Yang, Q.L. He, R.E. Lyon, Y. Hu, Investigation of the flammability of different textile fabrics using micro-scale combustion calorimetry, Polym. Degrad. Stab. 95 (2010) 108-115.

[24] D.Y. Wang, A. Leuteritz, B. Kutlu, M.A. Landwehr, D. Jehnichen, U. Wagenknecht, G. Heinrich, Preparation and investigation of the combustion behavior of polypropylene/organomodified MgAl-LDH micro-nanocomposite, J. Alloy compound. 509 (2011) 3497-3501.

[25] S. Materazzi, S. Vecchio, L.W. Wo, S. De Angelis Curtis, TG-MS and TG-FTIR studies of imidazole-substituted coordination compounds: $\mathrm{Co}(\mathrm{II})$ and $\mathrm{Ni}(\mathrm{II})$-complexes of bis(1methylimidazol-2yl)ketone, Thermochim. Acta. 543 (2012) 183-187.

[26] X.L. Gu, X. Ma, L.X. Li , C. Liu, K.H. Cheng, Z.Z. Li, Pyrolysis of poplar wood sawdust by TG-FTIR and Py-GC/MS, J. Anal. Appl. Pyrol. 102 (2013) 16-23.

[27] N.B. Gao, A.M. Li, C. Quan, L. Du, Y. Duan, TG-FTIR and Py-GC/MS analysis on pyrolysis and combustion of pine sawdust, J. Anal. Appl. Pyrol. 100 (2013) 26-32.

[28] E. Părpărită, M.T. Nistor, M.C. Popescu, C. Vasile, TG/FT-IR/MS study on thermal decomposition of polypropylene/biomass composites, Polym. Degrad. Stab. 109 (2014) 1320.

[29] T. Ahamad, S.M. Alshehri, TG-FTIR-MS (Evolved Gas Analysis) of bidi tobacco powder during combustion and pyrolysis, J. Hazard. Mater. 199-200 (2012) 200-208.

[30] Y. Liu, X.R. Zhao, YL Peng, H. Peng, P. Zhu, D.Y. Wang. Effect of reactive time on flame retardancy and thermal degradation behavior of bio-based zinc alginate film, Polym. Degrad. Stab. (2016) DOI: 10.1016/j.polymdegradstab.2015.12.024.

[31] J. Piskorz, D. Radlein, D.S. Scott, On the mechanism of the rapid pyrolysis of cellulose. J. Anal. Appl. Pyrol. 9 (1986) 121-137.

[32] P. Rutkowski, Catalytic effects of copper (II) chloride and aluminum chloride on the pyrolytic behavior of cellulose, J. Anal. Appl. Pyrol. 98 (2012) 86-97.

[33] J. Piskorz, D. Radlein, D.S. Scott, On the mechanism of the rapid pyrolysis of cellulose. J. Anal. Appl. Pyrol. 9 (1986) 121-137.

[34] Q. Lu, X.C. Yang, C.Q. Dong, Z.F. Zhang, X.M. Zhang, X.F. Zhu, Influence of pyrolysis temperature and time on the cellulose fast pyrolysis products: analytical Py-GC/MS study, J. Anal. Appl. Pyrol. 92 (2011) 430-438. 


\section{Captions}

Figure $1 \mathrm{HRR}$ curve of iron alginate and sodium as a function of temperature

Figure $2 \mathrm{TG}$ and DTG curves of iron alginate

Figure 3 3D infrared spectra of evolved gases during iron alginate pyrolysis

Figure 4a FTIR spectra for the evolved gaseous products in gas phase of iron alginate

Figure 4b FTIR spectra for the evolved gaseous products in gas phase of iron alginate

Figure 5 FTIR spectra of typical groups as a function of temperature for iron alginate

Figure 6 Evolution curves of $\mathrm{M} / \mathrm{Z}=17,18$ and 44 during pyrolysis of iron alginate

Figure 7 Py-GC-MS detection of gaseous compounds obtained from pyrolysis of iron alginate

Figure 8 Speculative pyrolysis mechanism of iron alginate

Table 1 Data obtained from the MCC parameters of iron alginate

Table 2 Results of chemical formation pyrolysis products for iron alginate at $700{ }^{\circ} \mathrm{C}$ 